\title{
Role of Leaf Pubescence in Soybean Resistance to the False Melon Beetle, Atrachya menetriesi FALDERMANN (Coleoptera: Chrysomelidae)
}

\author{
Hiroo KanNo \\ Tohoku National Agricultural Experiment Station, Omagari, Akita 014-01, Japan
}

(Received 22 April 1996; Accepted 6 June 1996)

\begin{abstract}
The role of leaf pubescence in resistance of soybean to the false melon beetle (FMB), Atrachya menetriesi FALDERMANN, was investigated in the field and laboratory using genotypes of soybean with varying levels of pubescence on leaves. There was a negative correlationship between trichome density on leaves and levels of leaf damage caused by feeding of adult FMB. Most of the genotypes which exhibited a high level of resistance to FMB were highly pubescent. There was a clear difference in the damage level between the high pubescent variety, T-207, and the glabrous variety, Mumoh-hadaka, in dual-choice assays. The differences in the damage level between T-207 and Mumoh-hadaka did not change even after reciprocal application of methanol and $n$-hexane extracts and also squeezed plant sap of both varieties. Furthermore, when trichomes were removed by shaving a leaf of the pubescent variety, T-207, the beetle attack was overwhelmingly biased to the shaved part. SEM observations revealed only the normal type of trichomes, and no glandular trichomes, on the soybean leaf. All these facts suggest that leaf pubescence might be a major factor associated with the resistance of soybean to FMB.
\end{abstract}

Key words: Atrachya menetriesi, soybean, host plant resistance, pubescence, trichome

\section{INTRODUCTION}

The false melon beetle (FMB), Atrachya menetriesi Faldermann, is an important herbivorous insect pest of soybean in Japan. Adults generally appear in the field from early July to the end of August, and infest newly developed leaves of the vegetative soybean stage. The infestation of FMB results in extensive damage and crop loss (KUBO and ANDO, 1989).

Host plant resistance is, in general, a very important and useful control measure for insect pests. The use of resistant varieties is particularly advantageous in avoidance of environmental pollution by application of chemicals, and is also compatible with other components of an integrated pest management strategy.

The present research has therefore been carried out to evaluate soybean resistance to FMB and to elucidate its nature.

In this paper, the results of observations and tests are given with particular reference to the effect of leaf pubescence on feeding activity of the adult and the mechanism of resistance.

\section{MATERIALS AND METHODS}

Field observations on varietal differences in damage level. A high pubescent variety, T-207, and a glabrous variety, Mumoh-hadaka, were planted in the field in early June. The experimental plots were designed with three replications. Each plot was set in $30 \mathrm{~m}^{2}(5 \mathrm{~m} \times 6 \mathrm{~m})$. Six plants were randomly chosen in each plot on each sampling occasion to assess the 
percentage of leaves damaged by FMB feeding. The field observation was repeated three times in July, when the soybean plants were in the vegetative stage.

Adult feeding tests on different varieties in captivity. Thirty varieties of soybean with varying levels of leaf pubescence were also randomly selected in the field for breeding. Ten newly developed and expanded leaves were plucked from ten plants of each variety and then the number of trichomes on the midrib of $1 \mathrm{~mm}$ in length of the central part of each leaf was counted under a stereo-microscope with a micrometer. After that, the average number of trichomes on the midrib of $1 \mathrm{~mm}$ in length of the leaf in each variety was determined. The other ten leaves in each variety were collected from the field, and the leaf areas were measured using a leaf area meter. These leaves were individually put into separate Petridishes with single female adults of FMB. The Petri-dishes were kept under $25^{\circ} \mathrm{C}$ and $16 \mathrm{~L}-$ $8 \mathrm{D}$ photo regime. After $48 \mathrm{~h}$, leaf areas were measured again, as described before, to determine the amount fed on by the adult. The mean trichome densities were correlated to mean leaf areas fed on by the beetle.

Feeding preference assays. To determine the role of trichomes in host leaf preference, a dual-choice assay for FMB feeding was conducted using newly developed leaves of the high pubescent variety, T-207, and the glabrous one, Mumoh-hadaka, collected from the field. Paired leaves of the respective varieties were put into a Petri-dish, and a female adult was introduced. Ten Petri-dishes prepared by this procedure were kept under $25^{\circ} \mathrm{C}$ and $16 \mathrm{~L}-$ $8 \mathrm{D}$ photo regime. After $48 \mathrm{~h}$, the amount of feeding of FMB was determined as described above. Furthermore, three additional preference assays were performed to estimate the effect of chemical substances extracted from soybean leaves. Unless otherwise mentioned, the procedures employed were essentially the same as the case described above. In the first series, methanol extracts were applied to the test leaves. For this purpose, $10 \mathrm{~g}$ of the newly developed leaves from each variety, T-207 and Mumoh-hadaka, were collected in the field, and soaked in $300 \mathrm{ml}$ methanol for $24 \mathrm{~h}$ at room temperature. The methanol solutions obtained were filtrated through a filter paper, Toyo filter paper No. 2, and were then concentrated to approximately $30 \mathrm{ml}$ by a rotary evaporator. The concentrated solutions were reciprocally applied on the leaf surface of the two varieties using a paint brush. The second series was conducted using the $n$-hexane extracts, for which the preparation procedure was completely the same as in the case of the methanol extracts. Two solvents, methanol and $n$-hexane, were used for extraction of leaves to cover a wider range of chemicals extracted. In the third series, squeezed leaf saps were used. A hundred grams of leaves of each variety in about $30 \mathrm{ml}$ of distilled water were crushed with a homogenizer, and then squeezed by a squeeze machine. The squeezed leaf sap was then applied to the leaves. Finally, another assay was done using ten leaves of the T-207, from each of which the trichomes on the right half were shaved away by a razor. The shaved leaves were individually put in a Petri-dish with an adult female. After 2 days, the leaf damage was examined.

Observation of fine structures on soybean leaf surface. Observations of the fine structures of the leaf surface in three resistant (T-207, Sohden and Himeshirazu) and three susceptible (Mumoh-hadaka, Sayamusume, Tomoyutaka) soybean varieties were undertaken. Newly developed and expanded leaves of these varieties were collected from the field, and observed by scanning electron microscope. 


\section{RESULTS}

Observations on varietal differences in damage level

In the field, the percentage of damaged leaves in the pubescent variety, T-207, was consistently far lower than that in the glabrous one, Mumoh-hadaka, as shown in Fig. 1. The damaged leaves, even in the glabrous variety, gradually increased with the time elapsed. However, the great difference observed in the damage level between them was not affected.

\section{Adult feeding tests on different varieties in captivity}

Having examined the results of 30 varieties inclusively, a clear negative correlation, $r=$ -0.738 , was found between the mean trichome density of newly developed leaves and the mean area fed on by adult females of FMB (Fig. 2). The damage level was clearly lowered in parallel with the increase in the density of leaf pubescence.

\section{Feeding preference assays}

There was a clear difference in damage level between the two varieties used, as shown in Fig. 3. FMB adults mainly selected the glabrous variety, Mumoh-hadaka, so that the damage level in the high pubescent variety, T-207, was apparently lower than in the glabrous one. The mean leaf areas fed on FMB in pubescent and glabrous varieties were $0.18 \pm 0.06 \mathrm{~cm}^{2}$ and $3.68 \pm 0.37 \mathrm{~cm}^{2}$, respectively, as shown in the "control" column of Fig. 4. Figure 4 also indicates that the additional preference tests afforded results that were quite similar to those of the preceding test, with no significant differences between them. This implies that the application of the methanol and $n$-hexane extracts and the squeezed leaf sap to the leaf displayed no appreciable effect on the feeding. There were no significant differences in the results compared with those in the preference assay with untreated leaves. In the final assay, furthermore, FMB adults intensively attacked the right half of the leaf with the shaved trichomes, as shown in Fig. 5.

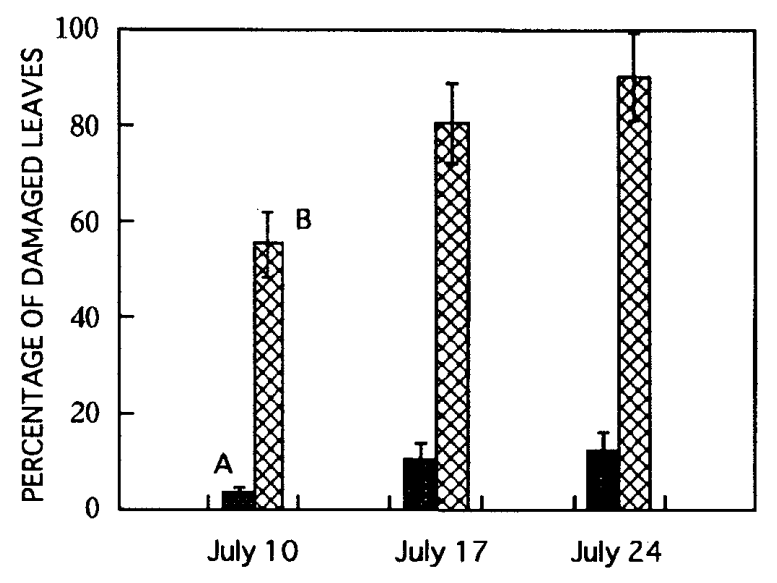

Fig. 1. Differences in damage level between pubescent and glabrous varieties in the ficld. A: pubcscent variety (T-207), B: glabrous variety (Mumoh-hadaka). Bars in the graph indicate standard errors $(n=18)$.

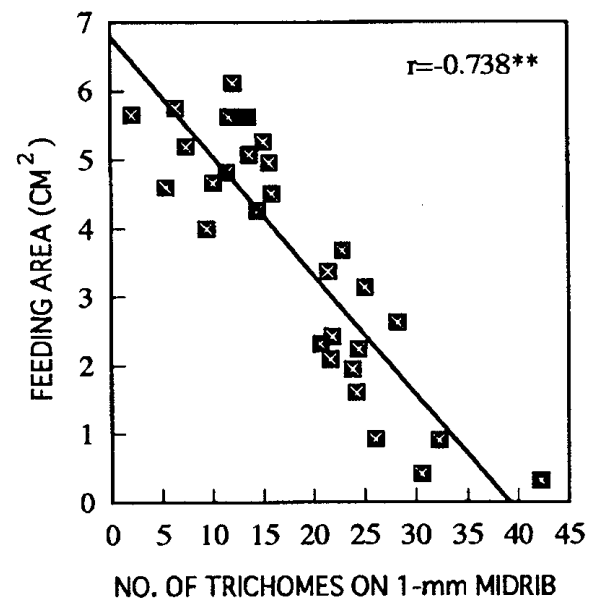

Fig. 2. Corrclation between trichome density and leaf area fed on by FMB. 


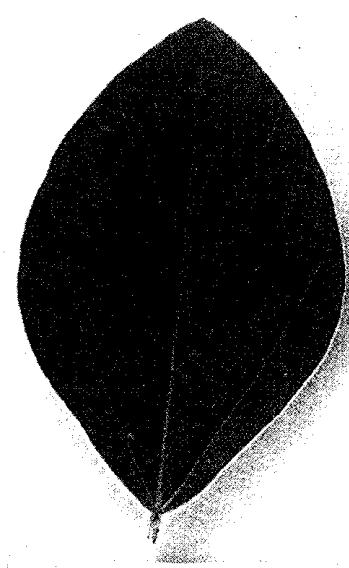

$T-207$

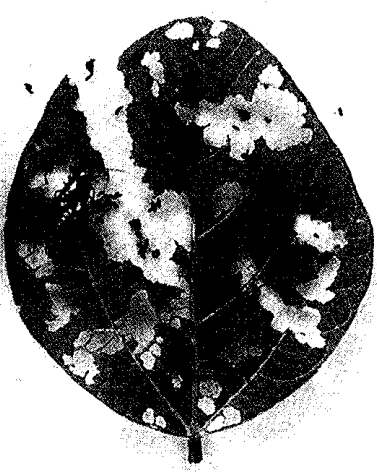

無毛裸

Fig. 3. Differences of FMB feeding between pubescent and glabrous varieties. Left: pubescent variety (T-207), right: glabrous variety (Mumoh-hadaka).

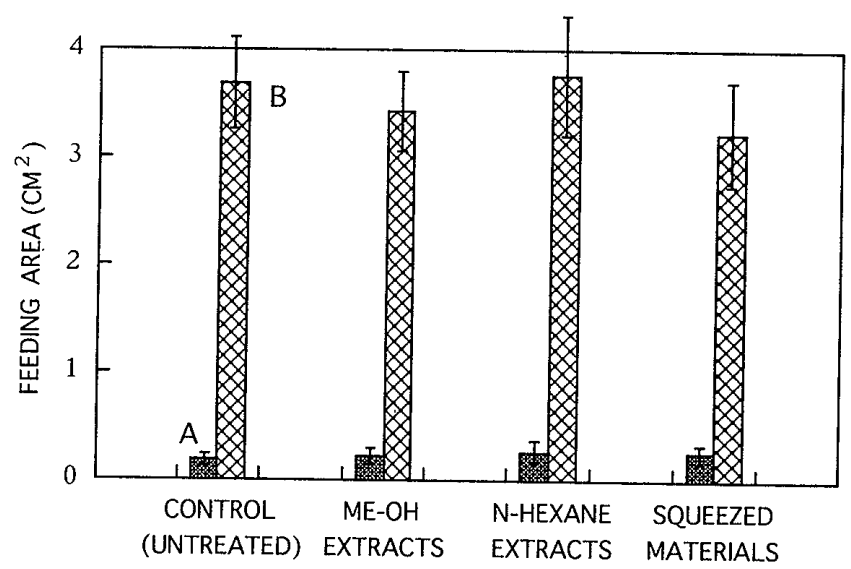

Fig. 4. Effect of $\mathrm{Me}-\mathrm{OH}$ and $n$-hexane extracts and also squeezed materials of the leaves on feeding activity of FMB. A: pubescent variety (T-207), B: glabrous variety (Mumoh-hadaka). Control indicates preference test using leaves of both $\mathrm{A}$ and $\mathrm{B}$ varieties without any treatments. The bars in the graph indicate standard errors $(n=10)$.
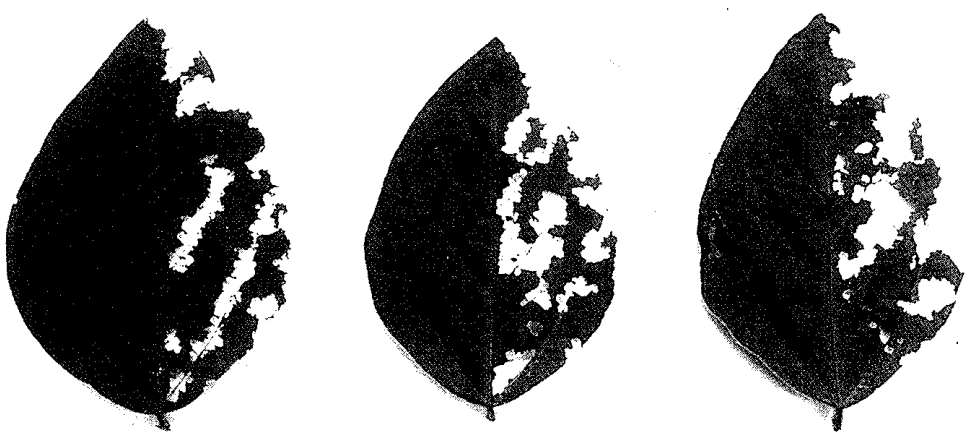

Fig. 5. Effect of trichomes on FMB feeding. Right half of the leaf: trichomes removed by shaving, left half of the leaf: control (non-treatment). 


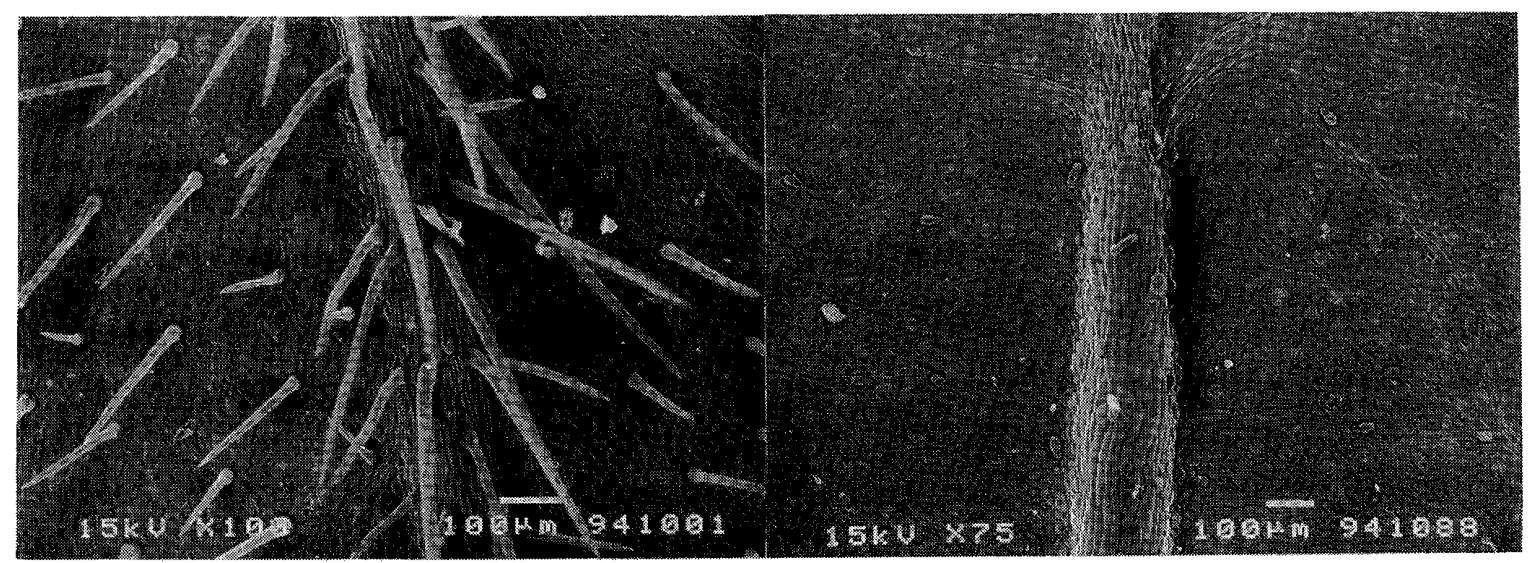

Fig. 6. Fine structures of leaf surface in both the pubescent variety (T-207) (left) and the glabrous variety (Mumoh-hadaka) (right).

\section{Observations of fine structures of leaf surface}

The three resistant varieties were high pubescent, while the other three susceptible ones were glabrous or low pubescent. Figure 6 exemplifies the magnified surfaces of newly developed and expanded leaves of both the high pubescent variety, T-207, and the glabrous one, Mumoh-hadaka. In the former, trichomes, which look like thorns, were located just on the midrib, vein and venule. The length of the longest trichome is around $0.8 \mathrm{~mm}$. There were no glandular trichomes on the leaves of any of the six soybean varieties observed.

\section{DISCUSSION}

The role of leaf pubescence in host plant resistance to herbivorous insects has been demonstrated in soybean (TAMURA, 1952; NishijImA, 1960; Broersma et al., 1972; Kogan, 1972; Turnipseed, 1977; Gunasinghe and Irwin, 1985; Khan et al., 1986) and also in many other plants, such as potato, tomato, wheat, sugarcane, alfalfa and cotton (Schillinger and Gallun, 1968; Belcher and Thurston, 1982; Treacy et al., 1986; Dimock and Tingey, 1987, 1988; Sosa, 1988; Goffreda et al., 1989). In a few soybean pests, i.e. Leguminivora glycinivorella and Asphondylia sp., it has been reported that pubescence sometimes acts as a stimulation for oviposition, leading to higher level damage (NISHIJIMA, 1960; TAMURA, 1952). KOGAN (1972) stated that there is no evidence suggesting an influence of leaf pubescence on the acceptance of soybean varieties by the Mexican bean beetle, Epilachna varivestis. In most cases, however, hairy plants with both glandular and non-glandular trichomes indicate resistant aspects to the insect pests through a reduction of larval feeding caused by mechanical and chemical effects, deterrence of adult oviposition and inhibited movement of larvae and adults. Broersma et al. (1972) and Turnipseed (1977) described that the glabrous strains of soybeans were damaged by higher populations of the potato leaf hopper, Empoasca fabae, than the other strains.

In some other plants, similar types of phenomenon have also been confirmed. DANIELSON et al. (1987) demonstrated that the pubescent varieties of alfalfa have a deleterious effect on the adult alfalfa weevil, Hypera postica. In particular, feeding activity of the weevils was lower on high pubescent varieties than on low pubescent ones. In the black vine weevil, Otiorhynchus sulcatus, leaf pubescence of beach strawberry was a very important factor 
concerning its resistance. The density of simple hairs on the abaxial leaf surface was negatively correlated with weevil feeding. Consequently, the fecundity of the weevil was apparently lower on pubescent varieties than it was on the others (Doss and SHANks, 1988). DimOCK and Tingey $(1987,1988)$ also mentioned that larvae of the Colorado potato beetle fed less frequently on leaves of the resistant wild potato, Solanum berthaultii than on leaves of cultivated potato, $S$. tuberosum. They emphasized that larval feeding is inhibited by trichomes on leaves of $S$. berthaultii, and that trichomes may influence the mechanical effect to the beetles.

In this research, the adult feeding activity of FMB was clearly suppressed on pubescent soybean varieties, as compared with that on glabrous and low pubescent varieties, in the field as well as in the free choice preference test in the laboratory. The results of the additional preference tests using leaves reciprocally treated with leaf extracts and squeezed leaf saps suggested that chemical substances contained in leaves may be of minor importance for the varietal differences in FMB feeding, and that the major contribution to the FMB resistance may be afforded by the leaf pubescence through its mechanical stimuli. This was also strongly supported by the results of another preference test using leaves with shaved trichomes; the adult beetles fed overwhelmingly on the shaved part within the same leaf where trichomes had been removed. As for the cabbage looper, Trichoplusia ni, KHAN et al. (1986) reported that when the trichomes on the leaf of the resistant soybean varieties, PI227687 and Davis, were shaven off, these leaves clearly became susceptible to larval feeding, as compared with unshaven leaves. Similarly, BAUR et al. (1991), with regard to the chrysomelid beetle, Agelastica alni, also described that removal of trichomes by shaving demonstrated a highly significant effect on the feeding behaviors of adults and larvae in dual-choice assays. Furthermore, the observation by scanning electron microscope confirmed the lack of glandular trichomes on the leaves of six soybean varieties including three resistant ones. This result rules out the possibility that chemical substances excreted from glandular trichomes play some role in soybean resistance to FMB.

It is concluded from these experiments that trichomes on soybean leaf might act as mechanical barriers to feeding by the adult FMB. Therefore, leaf pubescence is likely to be an important factor in suppressing the FMB damage by affording resistance of soybean varieties in the field.

\section{ACKNOWLEDGEMENTS}

The author thanks Dr. H. SAITo, Head of Plant Pathology Division, Tohoku National Agricultural Experiment Station, for his kind assistance regarding SEM observation, and Dr. R. BAUR, Swiss Federal Research Station, for his critical reading of the manuscript.

\section{REFERENCES}

BAUR, R., S. BINDER and G. BENZ (1991) Nonglandular leaf trichomes as short-term inducible defense of the grey alder, Alnus incana (L.), against the chrysomelid beetle, Agelastica aluni L. Oecologia 87: 219-226.

Belcher, D.W. and R. ThuRston (1982) Inhibition of movement of larvae of the convergent lady beetle by leaf trichomes of tobacco. Environ. Entomol. 11: 91-94.

Broersma, D.B., R.L. Bernard and W.H. Luckmann (1972) Some effects of soybean pubescence on populations of the potato leafhopper. J. Econ. Entomol. 65: 78-82.

Danielson, S.D., G.R. MANGlitz and E.L. SoRensen (1987) Resistance in perennial glandular-haired Medicago species to feeding by adult alfalfa weevils, Hypera postica GillenHAL (Coleoptera: Curculionidae). Environ. Entomol. 16: 708-711.

Dimock, M.B. and W.M. Tingey (1987) Mechanical interaction between larvae of the Colorado potato 
beetle and glandular trichomes of Solanum berthaultii Hawkes. Am. Potato J. 64: 507-515.

Dimock, M.B. and W.M. TingeY (1988) Host acceptance behavior of Colorado potato beetle larvae influenced by potato glandular trichomes. Physiol. Entomol. 13: 399-406.

Doss, R.P. and C.H. SHANks (1988) The influence of leaf pubescence on the resistance of selected clones of beach strawberry (Fragaria chiloensis L. DucheSNE) to adult black vine weevils (Otiorhynchus sulcatus F.). Sci. Horticul. 34: 47-54.

Goffreda, J.C., M.A. Mutchler, D.A. Ave, W.M. Tingey and J.C. Steffens (1989) Aphid deterrence by glucose esters in the glandular trichome exudate of the wild tomato, Lycopersicon pennellii. J. Chem. Ecol. 15: $2135-2147$.

GunAsINGHE, U.B. and M.E. IRwIN (1985) Effect of soybean pubescence on aphid probing behavior and transmission of soybean mosaic virus (SMV). Phytopathology 75: 1348-1349.

KHAN, Z.R., J.T. WARD and D.M. NORRIS (1986) Role of trichomes in soybean resistance to cabbage looper, Trichoplusia ni. Entomol. Exp. Appl. 42: 109-117.

Kogan, M. (1972) Feeding and nutrition of insects associated with soybeans. 2. Soybean resistance and host preferences of the Mexican bean beetle, Epilachna varivestis. Ann. Entomol. Soc. Am. 65: 675-683.

Kubo, T. and Y. Ando (1989) Food preference of a polyphagous leaf beetle, Atrachya menetriesi FaLdermann (Coleoptera: Chrysomelidae). Jpn. J. Appl. Entomol. Zool. 33: 231-237.

Nishimima, Y. (1960) Host plant preference of the soybean pod borer, Grapholitha glicinivorella MATSUMURA (Lep., Eucosmidae). Ent. exp. appl. 3: 38-47.

Schilinger, J.A. and R.L. Gallun (1968) Leaf pubescence of wheat as a deterrent to the cereal leaf beetle, Oulema melanopus. Ann. Entomol. Soc. Am. 61: 900-903.

SosA, O. (1988) Pubescence in sugarcane as a plant resistance character affecting oviposition and mobility by the sugarcane borer (Lepidoptera: Pyralidae). J. Econ. Entomol. 81: 663-667.

TAmura, I. (1952) Ecological studies on the soybean pod gall midge, Asphondylia sp. In Ecological Studies on the Insect Injury of Soybean Plant (I. TAMurA, ed.). Kantoh-Tohsan Natl. Agric. Exp. Stn., Konosu, pp. 154-236.

Treacy, M.F., J.H. Benedict, J.C. Segers, R.K. Morrison and J.D. LoPez (1986) Role of cotton trichome density in bollworm (Lepidoptera: Noctuidae) egg parasitism. Environ. Entomol. 15: 365-368.

TuRnipsEeD, S.G. (1977) Influence of trichome variations on populations of small phytophagous insects in soybean. Environ. Entomol. 6: 815-817. 